\title{
Application of spaced system of laser interferometers and tiltmeters for sharing the earthquakes precursory events
}

\author{
Mstislav Dubrov ${ }^{1 *}$, Victor Volkov ${ }^{2}$, Igor Larionov ${ }^{3}$, Jan Mrlina $^{4}$, Vaclav Polak ${ }^{4}$, Dmitriy \\ Aleksandrov $^{1}$ \\ ${ }^{1}$ Fryazino Branch of Kotel'nikov Institute of Radioengineering and Electronics RAS, Russia \\ ${ }^{2}$ Shmidt Institute of Physics of the Earth RAS, Russia \\ ${ }^{3}$ Institute of Cosmophysical Research and Radio Wave Propagation FEB RAS, Russia \\ ${ }^{4}$ Institute of Geophysics CAS, Czech Republic
}

\begin{abstract}
Our previous investigations evidently show that synchronous observation of global atmosphere and lithosphere disturbances by means of $130-1,600 \mathrm{~km}$ spatially distributed precise instruments is the effective method of detecting precursors of large seismic events and other dangerous natural phenomena. This study expands the spatial range of our search up to $7,000-8,000 \mathrm{~km}$ and allows regional and global disturbances to be shared.
\end{abstract}

\section{Introduction}

Solid earth movements forerunning strong earthquake can be detected at remote distances by precision geophysical instruments, which are able to measure small earth strains and tilts. Such instruments (e.g. laser strainmeter, accurate tiltmeter) being installed in accessible upper earth crust or sedimentary layers are inevitably affected by adjacent geospheres: underground water, atmosphere and ionosphere [1-4]. Abnormal instrument readings, which often observed at far distances [5] before strong earthquakes can be reasonable and qualified as earthquake precursor only if the detected affection process is global. Otherwise, it should be referred to local disturbance or instrumental obstacle.

The subject of presented investigation is the analysis of non-tidal strain-baric and tiltbaric processes recorded by system of ground-based laser interferometers within the Moscow Syneclise (Fryazino, Obninsk) [3, 6-8] and Kamchatka Peninsula (Karymshina) $[8,9]$ together with synchronously operating tiltmeter instruments of deep underground installations in the Bohemian Massif (Skalna, Jezeri, Pribram) [10, 11]. An applied method includes searching correlations between laser interferometers data and distant tiltmeters data before strong earthquakes. The goal is to distinguish the local, regional and global variations corresponding to abnormal pre-seismic and co-seismic processes.

Our first evaluable experience in this direction was the found statistically significant value of global coupling of strain-baric anomalies detected by means of distant Fryazino Kamchatka instruments using the Pearson's correlation technique [12]. This kind of data processing is applied here for time intervals included the 2015-2020 strong earthquakes.

*Corresponding author: mnd139@ire216.msk.su 


\section{Description of strain and tilt measuring instruments and methods}

Among the experimental methods and tools currently used to study geophysical processes, a special place is occupied by integrated methods and measuring systems with spatially separated instruments, united by a common platform for data collection and processing. Measurements of various deformations of solid earth, for example, such as volumetric expansion and contraction, tilt and shear deformations of the Earth's crust, carried out with their help, are fundamental research methods in geophysics, since they provide primary information for scientific analysis about the nature of the movement of the geological environment $[13,14]$. Studies of the nature and spatio-temporal dynamics of seismicdeformation geophysical wave fields become especially fruitful when using spatially distributed systems of synchronously operating instruments [15-17].

The results presented in this work were obtained using instruments installed at six observation points located at a distance from each other, differing in their geological structure, seismicity and tectonic activity. In the described experiments, we used laserinterferometric strain gauges (laser strainmeters) and pendulum tiltmeter installations.

Laser strainmeters installed at the Fryazino Beam-Waveguide (underground testing site), which have been developed and modernized for many decades [3, 6-8], are located in the aseismic zone within the Moscow Syneclise (observation point FRZ in Fig.1). The crystalline basement, which lies at a depth of 1400-1600 $\mathrm{m}$ in the area of the testing site, is complicated by faults and is coated with a thick sedimentary cover. Two laser strainmeters with $100 \mathrm{~m}$ basis measuring earth surface deformation in $\mathrm{N} 50^{\circ} \mathrm{W}$ and $\mathrm{N} 30^{\circ} \mathrm{E}$ directions are distanced by $400 \mathrm{~m}$ from each other. Laser beams are enclosed in steel underground pipes at a depth of $1.5-2 \mathrm{~m}$.

The nearest observation point is located at Obninsk Geophysical Observatory [18] (observation point OBN in Fig.1). Testing and experimental measurements by means of laser strainmeters was started in 2002 based on three-mirror laser interferometerdeformograph scheme. Strain records was obtained on 3-90 m basis with instrument installation at both underground flor of laboratory building and $30 \mathrm{~m}$ underground gallery.

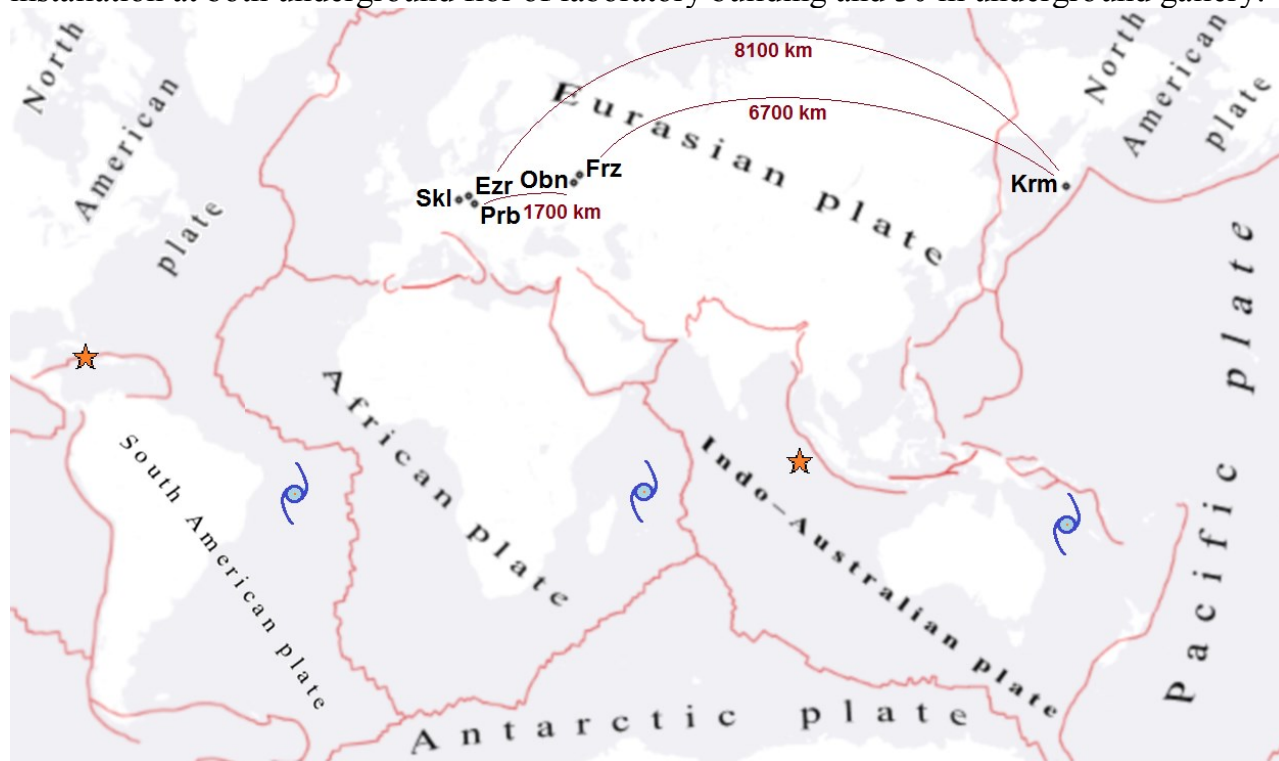

Fig. 1. Location of strain and tilt observation points: "Karymshina" KRM, "Fryazino" FRZ, "Obninsk" OBN, "Pribram" PRB, "Jezeri" JZR and "Skalna" SKL; earthquakes and tropical cyclones. 
A remote laser interferometer-strainmeter [8,9] has been operating since 2016 in the Kamchatka region, which is characterized by high seismic and volcanic activity. The $18 \mathrm{~m}$ measuring arm of the interferometer is oriented in the direction $\mathrm{N} 50^{\circ} \mathrm{W}$, which is perpendicular to the axis of the tectonic fault passing along the eastern coast of the Kamchatka Peninsula near the subduction zone (observation point "Karymshina" - KRM in Fig.1). This device is designed to conduct routine measurements of deformations of nearsurface sedimentary rocks and study the relationship between the geodeformation process and its derivatives, such as the generation of geoacoustic emission, variations in the strength of the surface electric field, etc.

Laser interferometric strainmeters measure changes in length $\Delta l$ of some basis with length $l$. Change in length $\Delta l$ is expressed in fraction of laser wavelength $(\lambda=632.8 \mathrm{~nm})$ and relative linear deformation is defined as $\varepsilon=\Delta l / l$. A detailed description of used laser strainmeters and their interferometric recording system is given in $[8,9]$. The highest resolution of interferometric recording servo-system of compensation type had been approved up to $0.01-0.001 \mathrm{~nm}$ in a $1 \mathrm{~Hz}$ band. The basic accuracy of the digital modulation recording system is $\lambda / 2=316 \mathrm{~nm}$ (Fig. 2 e, Fig. 3 a and Fig. $4 \mathrm{~h}$ ) and $\lambda / 4=158 \mathrm{~nm}$ (Fig. 5 b), while appropriate tuning the interferometer modulation and acquisition software allows the resolution to be improved up to $1.0-0.1 \mathrm{~nm}$ [8]. Frequency-stabilized and thermally controlled He-Ne lasers are used as radiation sources in the strainmeter schemes.

Observations of earth tilts have been carried out by mean of accurate pendulum tiltmeters installed at tree tidal observatories located in the Bohemian Massif $[10,11]$. Pribram Observatory (Central Bohemia, observation point PRB in Fig.1) is located in a deep abandoned mine at a depth of $90 \mathrm{~m}$. Skalna Observatory is located in the West Bohemia seismically active region in an underground gallery in a granite block at a depth of $10 \mathrm{~m}$ (observation point SKL in Fig.1). The tiltmeter in Jezeri Observatory (North Bohemia, observation point JZR in Fig.1) is installed in a gallery about $40 \mathrm{~m}$ underground, which is located at a junction of Neogene clastic and fractured zone.
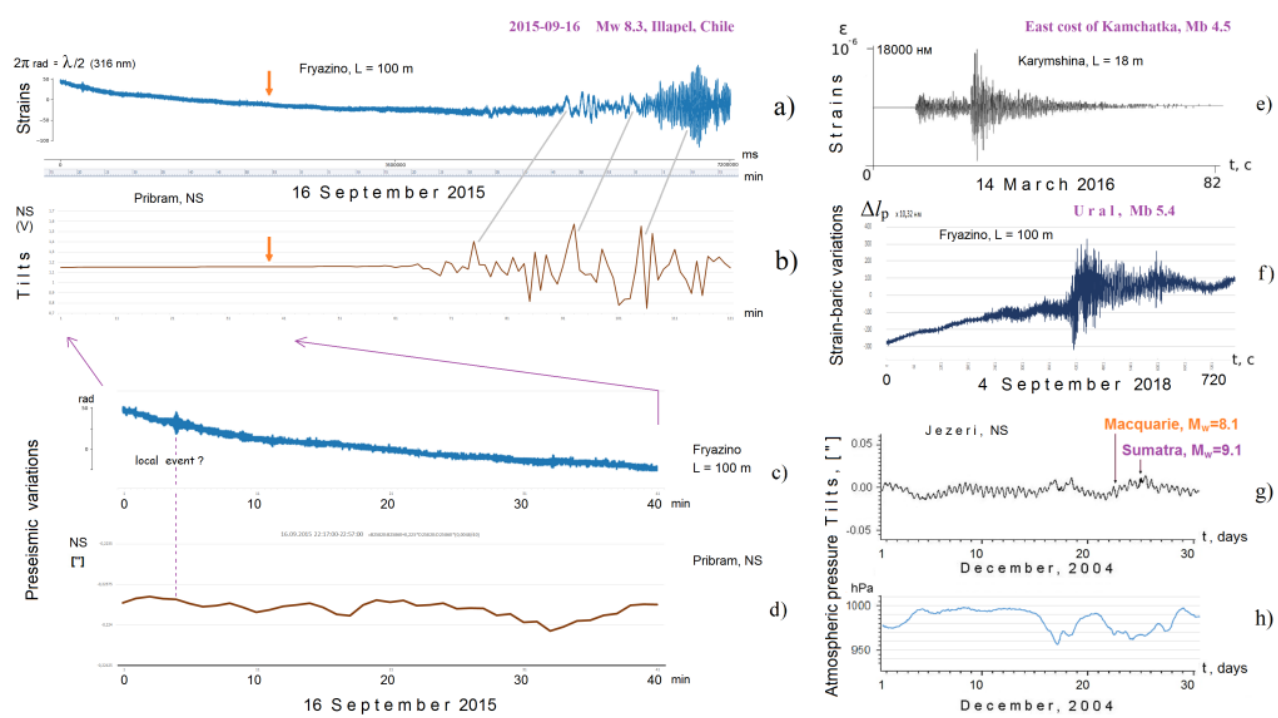

Fig. 2. The examples of strain and tilt registrations: Illapel, Chile Mw 8.3 earthquake on 16 Sep 2015 recorded at FRZ (a, c) and PRB (b, d) observational point; east coast of Kamchatka Mb 4.5 earthquake on 14 Mar 2016 recorded at KRM point (e); Ural Mb 5.4 earthquake on 4 Sep 2018 recorded at FRZ point (f); strain-baric variation at JZR point in December 2004 (g, h). 
Two-component tiltmeters measuring earth tilts in NS and EW directions are describe in detail in $[10,11]$. The resolution of tiltmeters with vertical pendulum is estimated as 1 milliarcsecond (mas) in tidal channel and 0.1 mas in seismic-accelerometer channel. Tiltmeter with horizontal pendulum installation has resolution about 0.1 mas in tidal channel and 0.01 mas in seismic-accelerometer channel.

Selective examples of strain and tilt registrations at four observational point are shown in Fig. 2. The records are obtained by means of two $100 \mathrm{~m}$ laser strainmeters at observation point "Fryazino" FRZ (Fig. 2 a, c, f), 18 m strainmeter at observation point "Karymshina" KRM (Fig. 2 e), accurate pendulum tiltmeters at observation points "Pribram" PRB (Fig. 2 b, d) and "Jezeri" JZR (Fig. 2 g).

The joint strain and tilt records of the Illapel, Chile Mw 8.3 earthquake on 16 September 2015 are presented in Fig. 2 a-d. The registration at observation point FRZ is performed by $100 \mathrm{~m}$ equal-arm interferometer-strainmeter $[6,8]$, which measures the length difference between two mutually perpendicular arms and is rid of baric and other meteorology obstacles. The strain records (Fig. 2 a, c) are unfiltered wideband data obtained with $0.5 \mathrm{~ms}$ sampling rate and the tilt recording signals (Fig. 2 b, d) are filtered and are digitized with 1 min sampling rate. Pre-seismic strain and tilt variations $40 \mathrm{~min}$ before Illapel $\mathrm{Mw} 8.3$ earthquake are depicted in Fig. 2 c, d. Local events and weak global disturbances can be distinguished by means of spatially distributed system of strainmeters and tiltmeters, which are sensitive to precursors of strong seismic and large atmosphere disasters [11, 19].

The records in Fig. 2 e and Fig. 2 f show earthquake registrations performed by two unequal-arm interferometer-strainmeters at observation points KRM and FRZ correspondingly. The local near east coast of Kamchatka Mb 4.5 earthquake on 14 March 2016 was recorded by means of sealed $18 \mathrm{~m} \mathrm{KRM}$ strainmeter at epicenter distance of 133 $\mathrm{km}$. The body and surface seismic waves are clearly distinguished, their maximum pick-topick amplitudes are near $18,000 \mathrm{~nm}$. The remote Ural Mb 5.4 earthquake on 4 September 2018 was recorded by means of FRZ strainmeter with $100 \mathrm{~m}$ measuring arm enclosed into underground steel pipe, which is partially connected with outer atmosphere. In addition of standard body and surface waves, this instrument records long-period 80-100 s strain-baric oscillations, of which relative strain amplitudes reach $\varepsilon=5 \cdot 10^{-9}$ (absolute displacements $\Delta l \sim 500 \mathrm{~nm}$ on $l \sim 100 \mathrm{~m}$ measuring basis, Fig. $2 \mathrm{f}$ ). In general, strain-baric interferometer output $\Delta l_{\mathrm{p}}$ signifies the linear function of $l$ and $P$ variations:

$$
\Delta l_{\mathrm{p}}=\mathrm{a} \cdot \Delta l+\mathrm{b} \cdot \Delta P,
$$

Therefore, $\Delta l_{\mathrm{p}}$ describes the combined instrument response to earth strain and atmospheric pressure variations [4]. This yields a definite opportunity to observe and jointly investigate both strain and baric processes by means of a secluded laser instrument.

It is important to note that strain-baric and tilt-baric affection manifests itself in any strainmeter or tiltmeter prototype recording as namely baric earth deformation or baric errors (correction) of used measuring instrument. A case example of such interaction is depicted in Fig. 2 g, h showing the synchronous records of tilts and atmospheric pressure at observation point "Jezeri" JZR one month before the Macquarie Mw 8.1 on 23 December 2004 and Sumatra Mw 9.1 earthquakes on 26 December 2004. Strong anti-correlation (correlation coefficient $R_{\mathrm{P}} \sim 0,9$ ) is evidently seen at these records: (1) joint tilt and baric variations on 18-19 December 2004, which correspond to ULF (Ultra-Low Frequency) $0.006 \mathrm{mHz}$ oscillations recorded these days [7, 11]; (2) near diurnal tilt-baric variations on 21-24 December 2004 corresponding to significant ionospheric modifications distinguished on 21 and 24 December 2004 [11].

The above example shows that raising wave activities in adjacent geospheres (atmosphere and ionosphere) are probably coupled with abnormal lithosphere processes and therefore, can be attributed to the earthquake precursors. 


\section{Study of earthquake precursors and tropical cyclone coupling}

In our recent publication [11], the atmosphere-lithosphere interaction preceding the major Macquarie Mw 8.1 and Sumatra Mw 9.1 earthquakes in December 2004 was considered as be connected to the most powerful cyclones (typhoons) activities of this season over NW Pacific and Indian Ocean in November-December 2004:

\section{MUIFA Category 4 SSHWS, 14-25 November NW Pacific \\ BENTO Category 519 November-04 December Indian Ocean}

\section{NANMADOL Category 429 November-04 December NW Pacific}

The hypothesis was a powerful cyclone development accompanied an earthquake preparation and caused earthquake triggering through Indo-Australian and Pacific tectonic plates swinging (see Fig 1). At the same time, precursory phenomena, including abnormal behavior of ultra-wideband $(0.002 \mathrm{mHz}-3 \mathrm{~Hz})$ oscillations of the Earth, was recorded at far distances up to $1,000-10,000 \mathrm{~km}[7,11]$.

The argument in favor of this statement is detecting the strain-baric and tilt-baric coupling at the regional level (Obninsk - Jezeri distance near 1,700 km) that was made provided by the comparison of laser strainmeter data from OBN with tilts recorded in JZR observational points (Fig 3).

This OBN interferometer-strainmeter prototype with $3 \mathrm{~m}$ measuring arm that was freely connected with outer atmosphere was installed at underground flor of laboratory building. Therefore, the strain-baric output $\Delta l_{\mathrm{p}}$ (Fig 3 a) is the combined instrument response to earth strain and atmospheric pressure variations: $\Delta l_{\mathrm{p}}=\mathrm{a} \cdot \Delta l+\mathrm{b} \cdot \Delta P$.

The comparing these data with JZR tilt measurements (Fig 3 b) gave the Pearson correlation coefficient $R_{\mathrm{P}}=0.92$ on 15-16 December 2004, i.e. in the period before the Macquarie Mw 8.1 and Sumatra Mw 9.1 earthquakes occurring. The correlation decreases down to $R_{\mathrm{P}}=0.85-0.67$ after earthquake finishing (Fig 3, right side).

It should be note that investigation of Macquarie - Sumatra co-seismic strains in longperiod domain (time intervals $\sim 100$ days before and $\sim 100$ days after earthquakes) recorded by two distant quartz extensometer yielded a two-fold increase in the correlation coefficient after these seismic events [13].
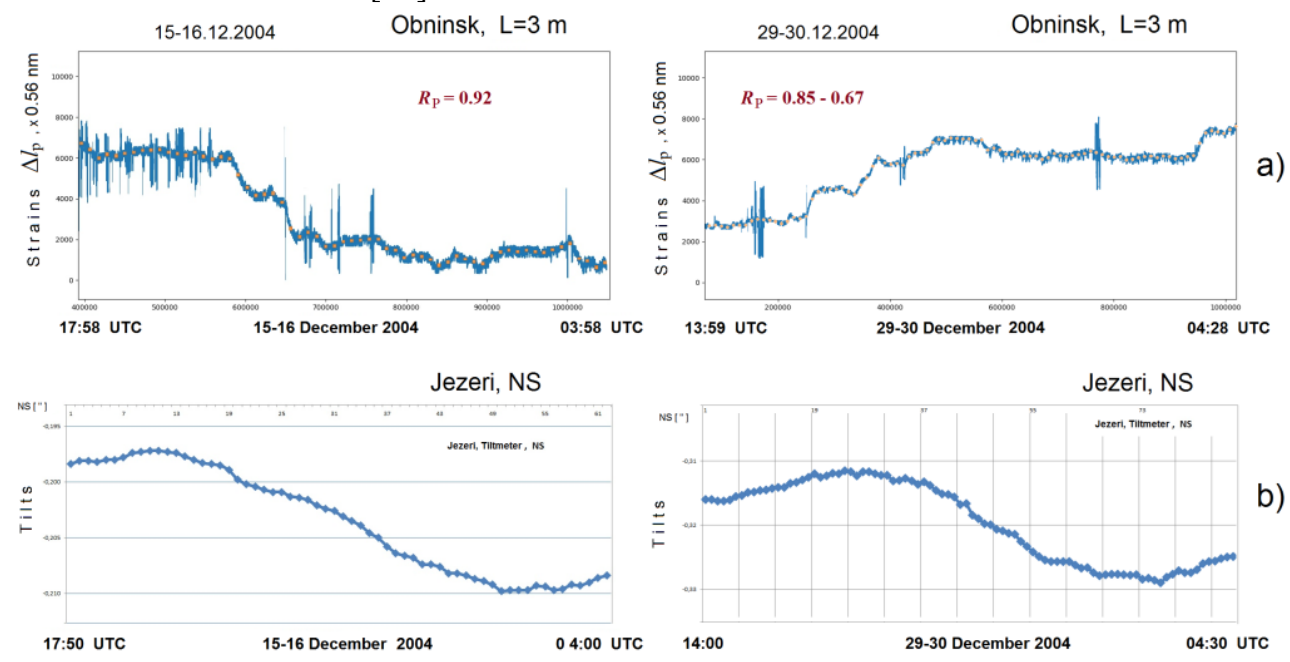

Fig. 3. Pre-seismic and post-seismic correlation of OBN strain-baric (a) and JZR tilts (b) variations in period of Macquarie Mw 8.1 and Sumatra Mw 9.1 earthquakes in December 2004. 
Our study of global coupling of strain-baric variations detected by means of distant Fryazino - Kamchatka instruments was carried out for another sufficiently strong off Southwest coast of Sumatra, Indonesia earthquake on 2 March 2016. This Mw 7.8 seismic event occurred in NE border region of Indo-Australian tectonic plate (see Fig.1). Fragments of its pre-seismic and co-seismic synchronous registration at three observational points are shown in Fig.4.

The obtained results show 10-40 min oscillations in PRB pressure (a), tilts (b) and in removed linear trend (c), which are correlated with KRM strains in removed linear trend (d) and pressure variations (e) 10-12 hours before earthquake occurring. Their feature is the temporal shift (phase retardation) in KRM oscillations relative PRB oscillations for a few minutes. The retardation is most clearly seen on the synchronous FRZ (f) and KRM (h) records during the standards surface Love $L$ and Raleigh $R$ waves arriving. The value of observed time retardation is order of $10 \mathrm{~min}$. The amplitude of these long-period oscillations, according to the registration data of two unequal-arm interferometersstrainmeters, is 3-4 times higher than the amplitude of the L- and R-waves recorded both at point FRZ (Fig. $4 \mathrm{f}$ ) and at point KRM (Fig. $4 \mathrm{~h}$ ). This indicates a probable baric origin of the recorded oscillations. An approximately two-fold decrease in the periods to 5-20 minutes of such oscillations on the tiltmeter record is associated with the spatial differentiation of the Earth's surface tilts under the influence of the deformation wave front.

Earlier [12], we suggested a possible connection the observed strain-baric processes during the earthquake on 2 March 2016 (Sumatra, Mw 7.8) with the development of a powerful tropical cyclone WINSTON (Category 5 SSHWS) in South Pacific over the border region between Indo-Australian and Pacific tectonic plates (see Fig. 1). It was the ending of this cyclone activity, which finished off the north coast of Australia on 3 March 2016. If we consider this intense atmospheric disturbance as a source of recorded longperiod oscillations, then it may be difficult to interpret the results obtained. Indeed, a wave with a characteristic period of 10-40 minutes (Fig. $4 \mathrm{f}, \mathrm{h}$ ) arrives at the registration point "Fryazino" earlier than at the point "Karymshina". Although, the first point is 1.6 times farther to the zone of cyclonic activity 03/02/2016 than the second point: the distance of the Coral Sea - Queensland (Australia, $20^{\circ} \mathrm{S} 150^{\circ} \mathrm{E}$ ) region from these points is $13300 \mathrm{~km}$ and $8100 \mathrm{~km}$, respectively.

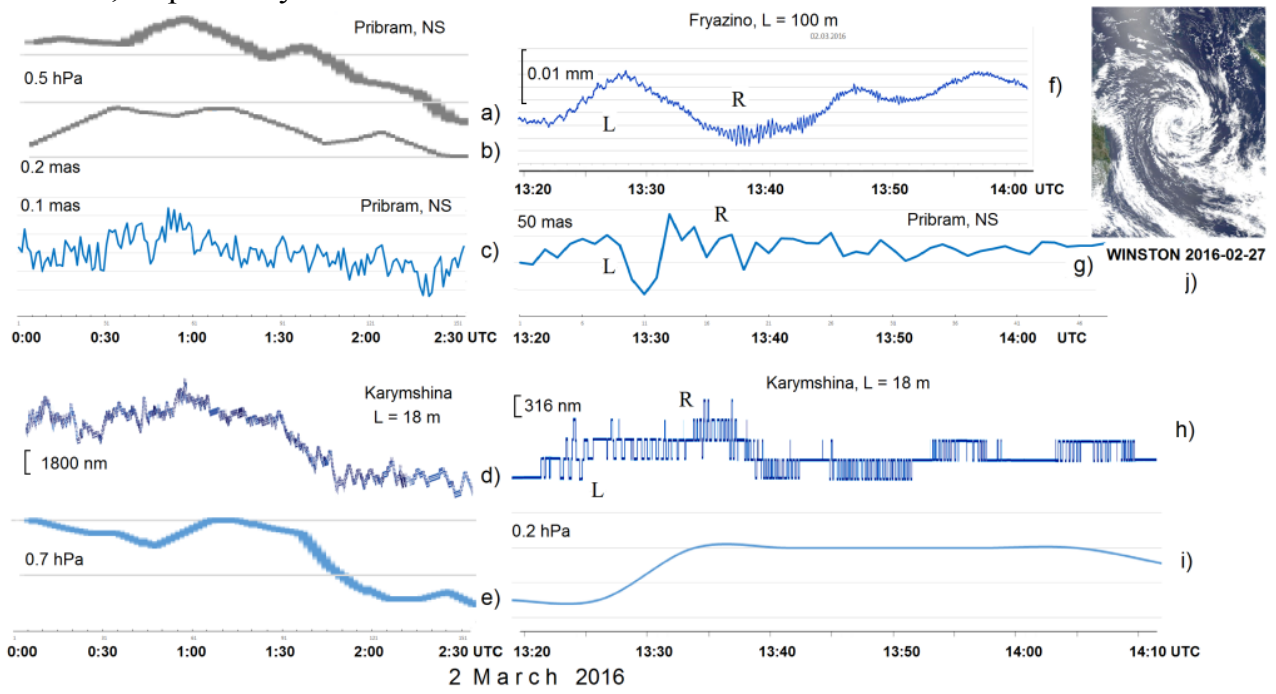

Fig. 4. Fragments of 2016 Sumatra Mw 7.8 earthquake pre-seismic and co-seismic synchronous registration at three observational point. Registration pre-seismic: PRB pressure (a), PRB tilts (b, c), KRM strains (d) and KRM pressure (e); co-seismic: FRZ strains (f), PRB tilts (g), KRM strains (h) and KRM pressure (i); Tropical cyclone WINSTON in South Pacific - Australian region (j). 
The apparent contradiction can be resolved by taking into account the spatial geometry of air flows and wave oscillations that are excited by a tropical cyclone (typhoon) in the upper atmosphere and in the ionosphere [20]. The plane of the wave front of such oscillations can be located at an angle of $40^{\circ}-60^{\circ}$ with respect to the line passing through the central region - the eye of a tropical cyclone (see the explanatory inset in Fig. $4 \mathrm{j}$ ). Taking into account that the vortex rotation of the cyclone air masses in the Southern Hemisphere occurs clockwise hence the wave vector of the excited waves in atmosphere and ionosphere [20] will have a significant component in the W-E direction. This model explains the fact that the wave front of the observed long-period oscillations reaches the "Karymshina" point with a time delay of 7-8 minutes relative to the "Fryazino" point, as shown in Fig. $4 \mathrm{f}, \mathrm{h}$. An additional confirmation of the baric origin of the recorded waves is the correlation between the signal of the laser interferometer-strainmeter and variations in atmospheric pressure at the "Karymshina" observational point (Fig. 4 i).

Let us consider strain-baric and tilt-baric interaction in the period of another $\mathrm{Mw} 7.7$ interplate earthquake, which happened on 28 January 2020. This earthquake occurred in the border region between South American and North American tectonic plates in Caribbean Sea, $123 \mathrm{~km} \mathrm{NNW}$ of Lucea, Jamaica (see Fig 1). Synchronous registration of this sufficiently strong seismic event carried out by two laser strainmeters installed at FRZ and KRM observational points and by accurate pendulum tiltmeter at PRB observational point (Fig. 5).

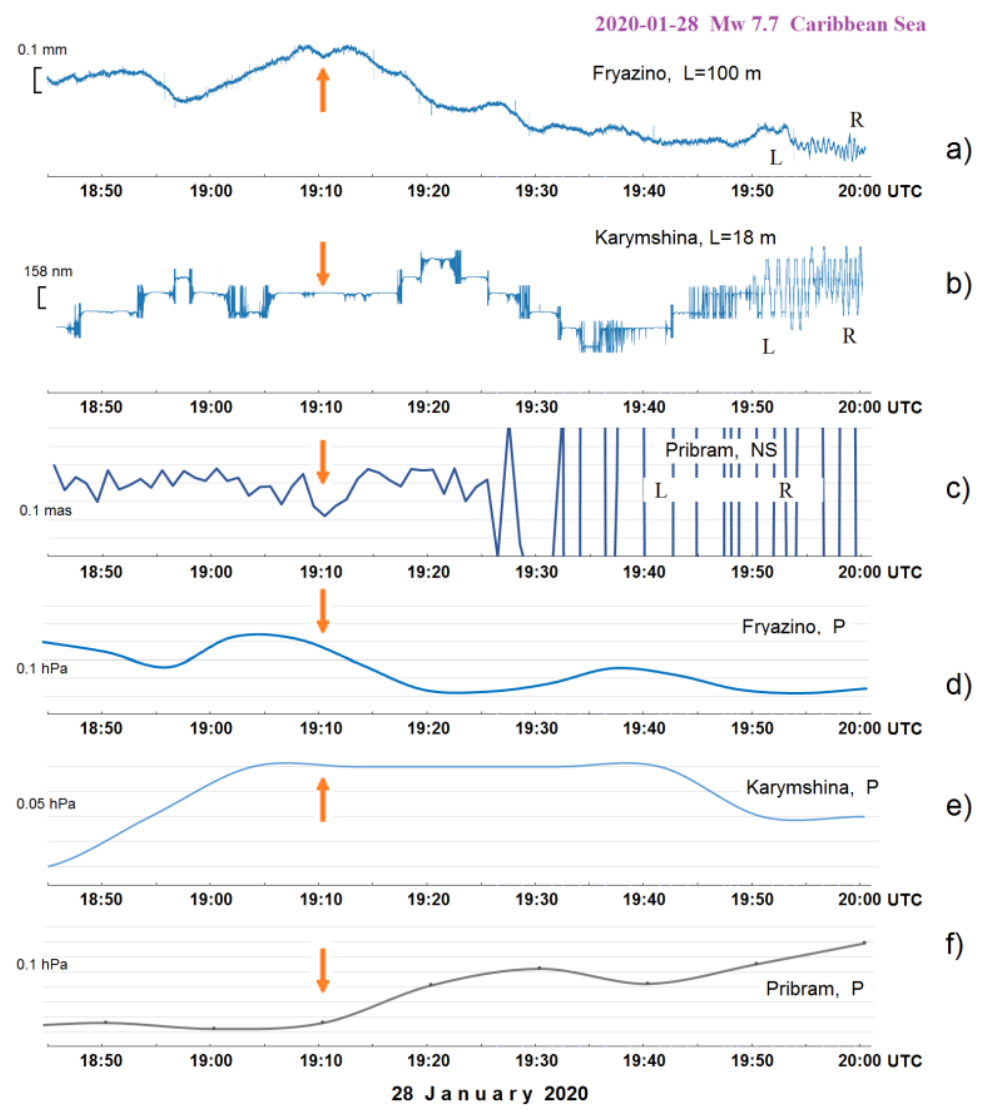

Fig. 5. Synchronous records of pre-seismic and co-seismic earth strain, tilt and atmospheric pressure variations at observation points "Fryazino" FRZ (a, d), "Karymshina" KRM (b, e) and "Pribram" PRB (c, f) in the period of Mw 7.7 earthquake in Caribbean Sea on 28 January 2020. 
The analysis of the obtained data show the featured correlation of strain-baric signals before and after the earthquake occurring $\left(t_{0}=19: 10: 25\right.$ UTC is pointed by vertical arrows in Fig. 5 records). Long-period 10-40 min oscillations of a replicated shape are observed on FRZ (a) and KRM (b) strain records. The feature and temporal shift (phase retardation) of KRM oscillations relative FRZ oscillations reiterate a picture of previous media interaction processes during Sumatra Mw 7.8 earthquake (Fig. 4 f, h).

The oscillation occur before earthquake starting, their amplitude exceeds the amplitude of the L- and R-waves sufficiently and the value of time retardation between KRM and FRZ phases is about of $8-10 \mathrm{~min}$. It means origin of these perturbations can be wave formed variations of atmospheric pressure that is confirmed by atmospheric pressure registrations (Fig. 5 d, e, f).

The PRB tilts recording (Fig. 4 c) reveals very small 5-20 min pre-seismic oscillation amplitudes (less than 0.1-0.2 mas) while the amplitudes of the L- and R-waves are manifold higher and reach $30-50$ mas. This is due to $1,700 \mathrm{~km}$ less epicentral distance of Caribbean Sea earthquake to PRB observational point than to FRZ point. In addition, strain-baric coefficients $b$ (see relation (1) in Section 2) of used ground-based laser strainmeters are much greater than corresponding coefficient of PRB tiltmeter of deep underground installation.

In return, we can glimpse a wonderful kick in FRZ and PRB records (Fig.5 a, b) that marked by vertical arrows at $t_{0}=19: 10$ UTC. It is just the time of the earthquake occurring and it appears on pressure records too (Fig.5 d, e, f) in form of irregular curves behavior. The shown phenomenon is not eventual as it is observed on our deformation and pressure records of some other strong earthquakes. This fact suggests that electromagnetic channel can be the permissible way of so fast transmission of seismic energy. Although other, e.g. gravitational channels cannot be excluded from the list of contenders.

The western movement of tropical cyclone activity from Indian Ocean basin into South Atlantics (www.wunderground.com/hurricane) distinguished the Caribbean Sea 2020 earthquake precursory period:

AMBALI 2019 Tropical cyclone Category 4, 3-7 December, SW Indian Ocean

CALVINIA 2019-2020 Tropical cyclone Category 1, 27 December - 1 January, SW Indian Ocean

CLAUDIA 2020 Tropical cyclone Category 1, 5-18 January, Australian region

KURUMI 2020 Subtropical storm, 21-25 January, South Atlantic

DIANE 2020 Severe tropical storm, 22 - 26 January, SW Indian Ocean

This movement ended by extremely rare event, namely subtropical cyclone development near Brazilian coast in South Atlantic. Subtropical storm KURUMI and Severe tropical storm DIANE, exciting the adjacent South American an African tectonic plates (see Fig.1) finalized an earthquake triggering process due to tropical cyclones swings: AMBALI CALVINIA - CLAUDIA - KURUMI - DIANE, which ended by Mw 7.7 earthquake in Caribbean Sea on 28 January 2020. The two last storms KURUMI and DIANE were the sources of strain-baric and tilt-baric precursors recorded in Central and East Europe as well in Far East region.

The vivid illustration of analyzed processes is shown in Fig.6. Atmospheric pressure variations synchronously recorded at two observation points SKL and JZR spaced at $90 \mathrm{~km}$ allows a singularity of local cyclonic motions on the day of Caribbean Sea earthquake occurring (Fig.6 a) to be displayed. Atmospheric depression (the minima on the pressure tracks at 11:10 and 13:00 UTC) moves from SKL to JZR point with phase velocity near 49 $\mathrm{km} / \mathrm{h}$. While motion of distinct phases is about two fold faster. 

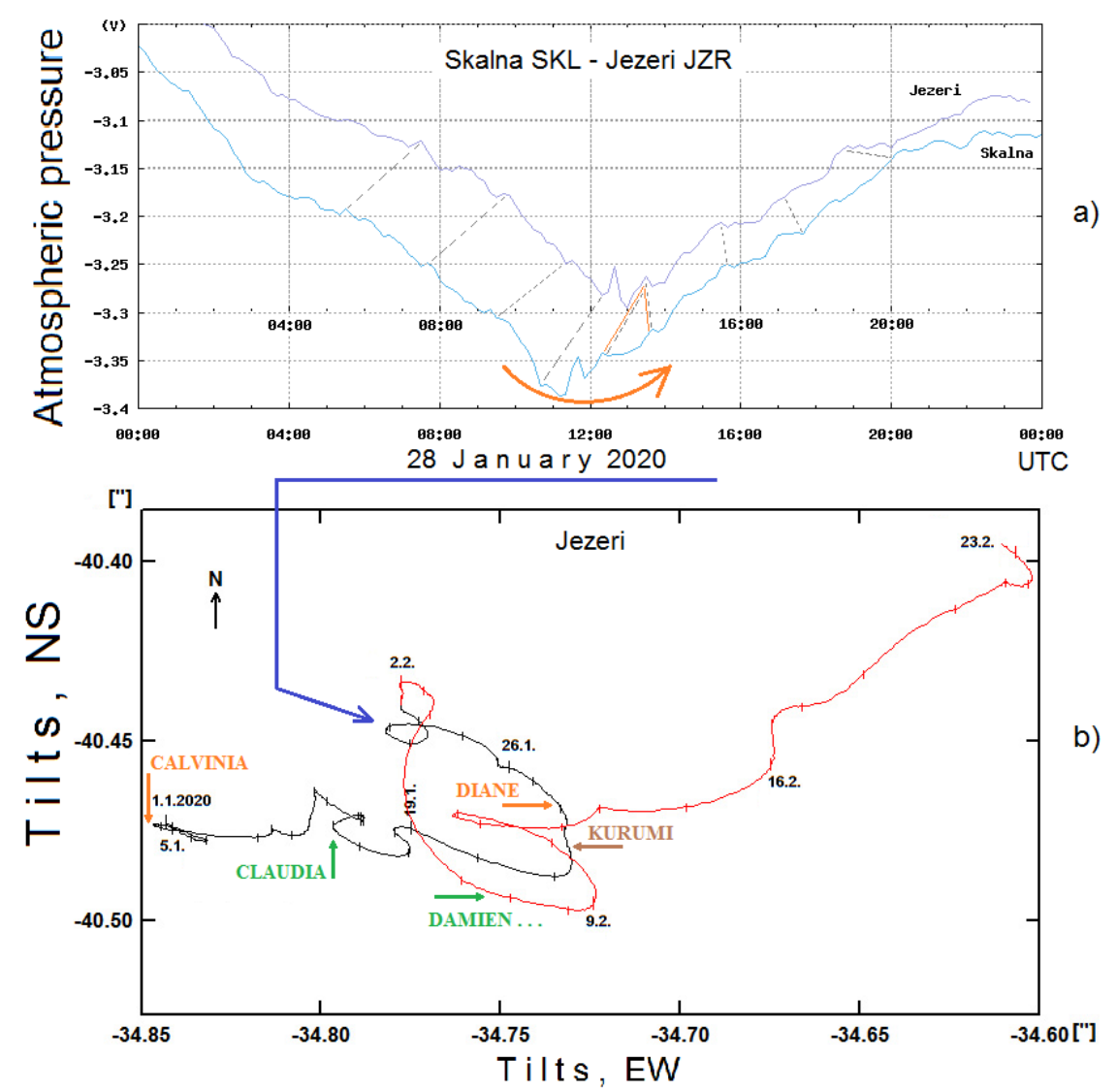

Fig. 6. Synchronous records of atmospheric pressure variations at observation points SKL and JZR on 28 January 2020 (a); vector representation of non-tidal tilts at observation point JZR during January February 2020 together with periods of five tropical cyclones CALVINIA - DAMIEN pointed (b).

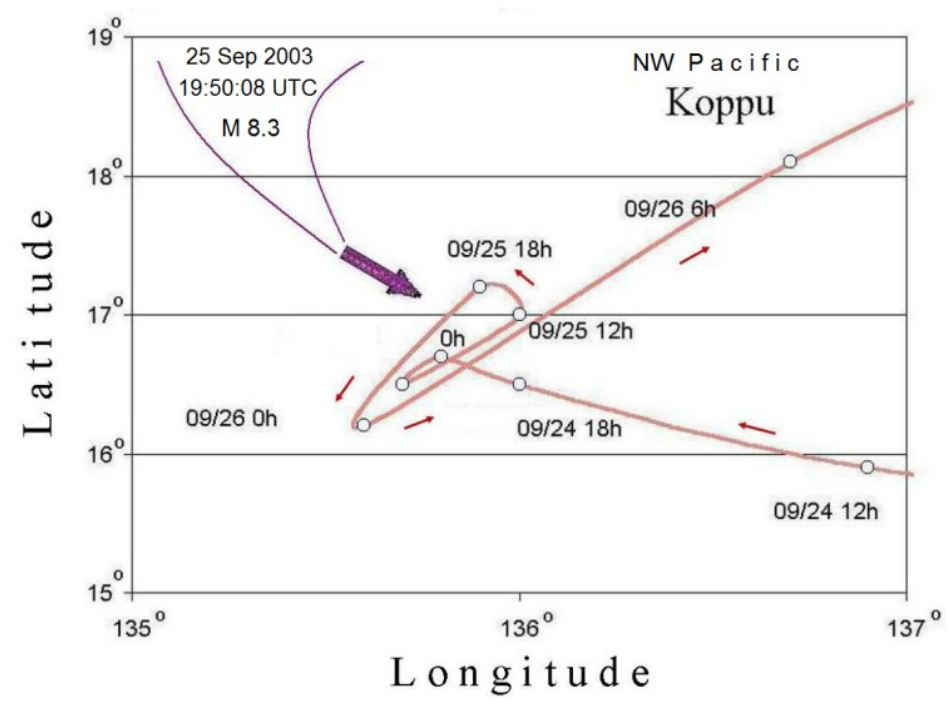

Fig. 7. Typhoon KOPPU in NW Pacific Ocean makes loops 20 hours before Hokkaido Mw 8.3 earthquake on 25 September 2003 [19]. 
There is time retardation in SKL phases relative JZR phases for two hours at 5:00-9:00 UTC period while SKL phase advance about of one hour is at 16:00-20:00 period (Fig.6 a). This means the curvilinear arc motion of atmospheric depression in SKL relative JZR observational point.

The loop cyclonic motions cause the loop-shaped tilt variations of the Earth's surface (Fig. 6.b). It is surprising that irregular non-tidal tilt variations are sensitive to the tropical cyclone motions, which develop more than $10,000 \mathrm{~km}$ apart of the point of tilts registration. At the same time, it is important that unusual tropical cyclone (hurricane, typhoon) behavior often occur before strong earthquakes.

This phenomenon we observed under studying the earthquake and hurricane coupling in various World Ocean basins. The example in Fig. 7 shows very strange typhoon KOPPU movements in NW Pacific Ocean 20 hours before Hokkaido Mw 8.3 earthquake on 25 September 2003 [19].

\section{Conclusion}

The novel techniques of the Earth's deformation measurements by means of strainmeter and tiltmeter systems spaced at far distances was applied for distinguish the global geophysical processes qualified as earthquake precursory phenomena. Experimental data arrays obtained at six observational points located at distances of $130-8100 \mathrm{~km}$ from each other have been processed and analyzed. The retarded long-period 10-40 min oscillations, which are recorded by far distanced instruments, appear due to powerful tropical cyclones excitation the tectonic plates as well as surface, atmosphere and ionosphere of the Earth. The study of strain- and tilt-baric processes preceding and accompanied three strong earthquake confirms our previous results and those together show decisively the coupling seismic events of global scale with World Ocean cyclonic activity.

\section{Acknowledgements}

The work was carried out within the framework of the state task 0030-2019-0014 and AAAA-A17-117080110043-4. Some work on recording and processing data in Czech observatory was supported by the CzechGeo/EPOS projects (No.LM-2010008 and LM2015079).

\section{References}

1. T. Jahr, Geodesy and Geodynamics, 9, 229-236 (2018)

2. M.N. Dubrov, O.S. Kazantseva, A.B. Manukin, V.I. Ponyatovskaya, Physics of the Solid Earth. 43, 404-411 (2007)

3. M.N. Dubrov, L.A. Latynina, R.F. Matveev, A.V. Ponomarev, Izvestiya Phys. Sol. Earth, 34, 983-990 (1998)

4. M.N. Dubrov, V.M. Smirnov, Geomagnetism and Aeronomy, 53, 1, 49-59 (2013)

5. I.L. Nersesov, L.A. Latynina, Tectonophysics, 202, 221-225 (1992)

6. Dubrov, M.N., Karmaleeva, R.M., Izv. Akad. Nauk SSSR Fiz. Zemli, 7, 81-89 (1976)

7. V.A. Volkov, M.N. Dubrov, Bull. d'Inform. des Marees Terrestres, 148, 11971-11986 (2014)

8. Dmitriy Aleksandrov, Mstislav Dubrov, Vasiliy Kravtsov and Igor Larionov, Experience in synchronous observation of seismic-strain oscillations of the Earth by the spaced 
laser interferometers, XI International Conference "Solar-Terrestrial Relations and Physics of Earthquake Precursors", Paratunka, Kamchatka region, Russia, September 22-25, 2020, E3S Web of Conferences, 196, 02010 (2020)

9. I. A. Larionov, Y. V. Marapulets, and B. M. Shevtsov, Solid Earth, 5, 1293-1300 (2014)

10. B. Košt’ák, J. Mrlina, J. Stemberk, B. Chán, Journal of Geodynamics, 52, 34-44 (2011)

11. Victor Volkov, Jan Mrlina, Mstislav Dubrov, Vladimir Smirnov, Sergey Golovachev, Vaclav Polak, Geodesy and Geodynamics, 11, 442-454 (2020)

12. D. V. Aleksandrov, M. N. Dubrov, I. A. Larionov, Yu. V. Marapulets, and B. M. Shevtsov, Journal of Volcanology and Seismology, 13, 3, 193-200 (2019)

13. L. Brimich, L. A. Latynina, I. Kohút, Contributions to Geophysics and Geodesy, 38, 4, 429-440 (2008)

14. Gy. Mentes, L. Brimich, M. Bednárik, J. Bódi, Comparison of extensometric results measured in the Vyhne Tidal Station and in the Sopronbánfalva Geodynamic

Observatory, 19th International Symposium on Geodynamics and Earth Tides, 22-26 June, 2021, Wuhan, China, Abstract book, p.33 (2021)

15. M. N. Dubrov and R. F. Matveev, Development and Study of Multicomponent Geophysical Laser Interferometer-Deformograph, J. Commun. Technol. Electron., 43, 9, 1068-1073 (1998)

16. M. N. Dubrov and D. V. Aleksandrov, Laser interferometer antenna array records seismo-acoustic earth strains, 6th International Conference on Antenna Theory and Techniques, Sevastopol, 2007, Publisher: IEEE, pp.307-308 (2007)

17. P. Spudich and J. B. Fletcher, BSSA, 98, 4, pp.1898-1914 (2008)

18. O.E. Starovoit, Vestnik VNTs, 5, 1, 8-12 (2005)

19. M.N. Dubrov, V.A. Volkov, S.P. Golovachev, Nat. Hazards Earth Syst. Sci. Discus. 2, 1, 935-961 (2014)

20. V.I. Zakharov, V.A. Pilipenko, V.A. Grushin, A.F. Khamidullin, Solnechno-zemnaya fizika, 5, 2, 114-123 (2019) 